\title{
Erratum to: The "survivin suppressants" NSC 80467 and YM155 induce a DNA damage response
}

\author{
Trevor G. Glaros • Luke H. Stockwin • \\ Michael E. Mullendore • Brian Smith • \\ Bethanie L. Morrison · Dianne L. Newton
}

Published online: 30 September 2012

(c) Springer-Verlag Berlin Heidelberg 2012

\section{Erratum to: Cancer Chemother Pharmacol}

DOI 10.1007/s00280-012-1868-0

In Fig. 2c, plus and minus symbols denoting treatment with NSC 80467 or YM155 were mistakenly swapped. This issue has been corrected; so that this figure demonstrates that treatment of the panel with either agent results in loss of survivin expression and enhanced levels of $\mathrm{pH} 2 \mathrm{AX} /$ pKAP1.

The revised figure is placed in the following page.

The online version of the original article can be found under doi:10.1007/s00280-012-1868-0.

T. G. Glaros - L. H. Stockwin - M. E. Mullendore - B. Smith ·

B. L. Morrison - D. L. Newton $(\square)$

Biological Testing Branch, Developmental Therapeutics

Program, Building 320, Room 9, SAIC-Frederick Inc.,

NCI-Frederick, Frederick, MD 21702, USA

e-mail: newtondianne@mail.nih.gov 
a

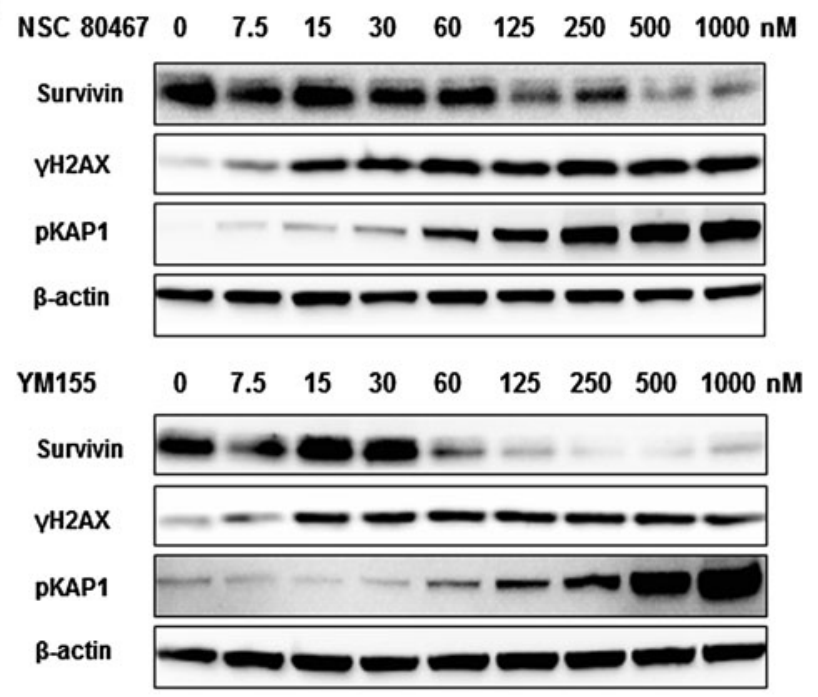

A549 HCT116 MCF7 PC3 U031 U251

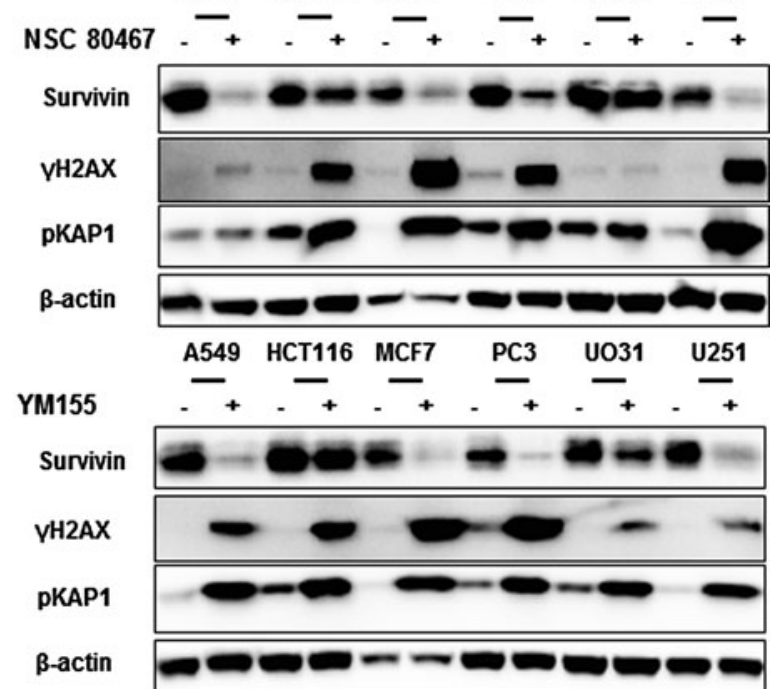

b

CONTROL

NSC80467
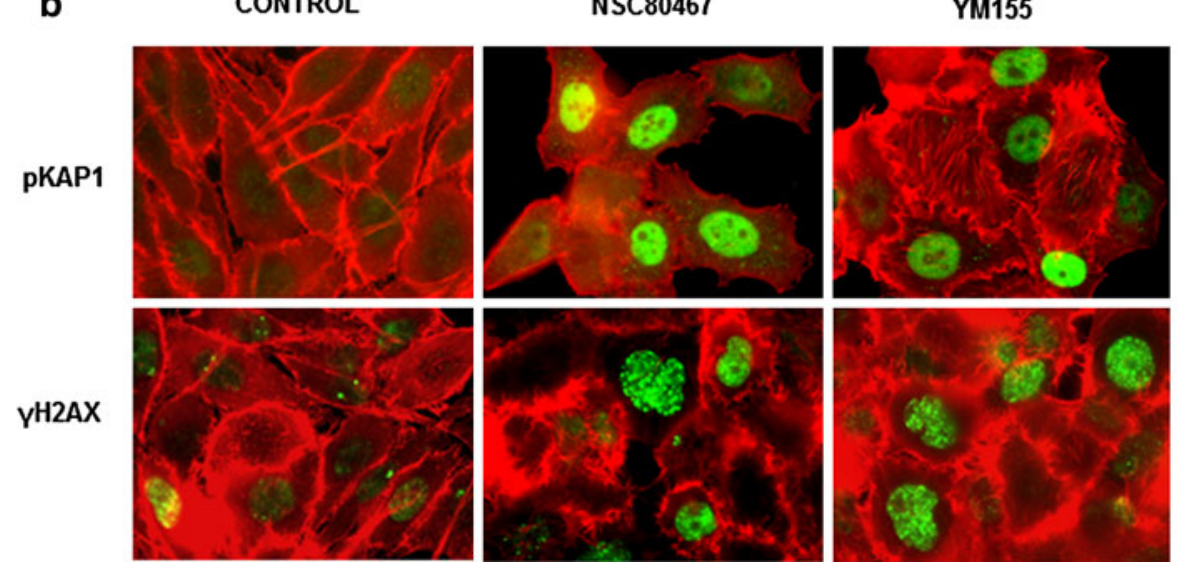

Fig. 2 Treatment with NSC 80467 and YM155 induces a DNA damage response. a PC3 cells were treated with NSC 80467 and YM155 at the indicated doses for $24 \mathrm{~h}$, cell lysate prepared and Western blotted for expression of survivin, cH2AX and pKAP1, b PC 3 cells on coverslips were treated with 400 nM NSC 80467 or
YM155 for $24 \mathrm{~h}$ and stained for expression of $\mathrm{cH} 2 \mathrm{AX}$ [green] and pKAP1 [green] with Phalloidin-Alexa555 counterstaining [red], c a panel of cell lines was treated with $400 \mathrm{nM}$ NSC 80467 and YM155 for $24 \mathrm{~h}$, lysate prepared and Western blotted for expression of survivin, $\mathrm{cH} 2 \mathrm{AX}$ and $\mathrm{pKAP} 1$ 